\title{
Dedication to Claudia Alexander
}

Published online: 23 November 2015

(C) Springer Science+Business Media Dordrecht 2015

As described in the Introduction, the aim of the International Cometary Workshop was to bring together the cream of the crop of cometary experts to discuss the role of comets in the understanding the origin and evolution of the solar system. The meeting was a great success, thanks not only to the work of the science and local organising committee led by Kathleen Mandt and Olivier Mousis, but also to the enthusiastic support of Claudia Alexander, the Project Scientist for NASA's role in the ESA Rosetta mission. Claudia Alexander passed away in July 2015, leaving behind a sense of great sadness for all involved with Rosetta, but also a strong legacy for the planetary science and space physics community.

Claudia worked at NASA's Jet Propulsion Laboratory. Following her work as project manager for NASA's Galileo mission, she was appointed Project Scientist for NASA's participation in the ESA Rosetta mission. I met Claudia very soon after I was assigned as the ESA project Scientist of Rosetta in 2013, and it was clear immediately that I had met a powerhouse in the community, a freight train of enthusiasm and somebody I knew I could immediately consider a friend and great colleague. In the months following Claudia and I worked at the project science tasks of optimising and stimulating science output of the mission, with Claudia helping me get up to speed with the new community I had joined. One highlight she flagged early on in our interactions was the International Cometary Workshop and I was very excited to attend. During the ICW meeting in the middle of a presentation Claudia strode up to me, with her signature beaming smile and declared "This is soooo great!! There is a real buzz! Can you imagine what we will be discussing next year!" It was indeed a great meeting and set the momentum for the cometary community for what was to come with Rosetta and we are still immersed in that scientific excitement.

A number of aspects of the success of Rosetta are only there because of Claudia, her work, her drive and her personality, her way of telling the world how important our work in planetary science and exploration is. In honour of her great contributions to the cometary research community, we dedicate this special issue to Claudia.

M. Taylor, Rosetta Project Scientist, ESTEC, ESA 